Çukurova Üniversitesi Mühendislik Mimarlık Fakültesi Dergisi, 31(ÖS 1), ss. ÖS 99-ÖS 108, Ağustos 2016

Cukurova University Journal of the Faculty of Engineering and Architecture, 31(ÖS 1), pp. SI 99-SI 108, August 2016

\title{
Cam Elyaf Kompozitlerin Alüminyum Plaka ile Yapıștırılması ve Yapışmanın Mekanik Özelliklerinin Araştırılması
}

\author{
M. Veysel ÇAKIR ${ }^{* 1}$, Didem KINAY ${ }^{2}$ \\ ${ }^{1}$ Gaziantep Üniversitesi, Havacılık ve Uzay Bilimleri Fakültesi, Uçak ve Uzay Mühendisliği \\ Bölümü, Gaziantep. \\ ${ }^{2}$ Gaziantep Üniversitesi, Havacılık ve Uzay Bilimleri Fakültesi, Uçak ve Uzay Mühendisliği \\ Bölümü, Gaziantep.
}

Geliş tarihi: 12.01.2016 Kabul tarihi: 04.04.2016

\section{Özet}

Özellikle havacılık endüstrisinde enerji verimliliğini artırmak ve ağırlı̆̆ı azaltmak için kompozit malzemelerin kullanımı giderek artmıştır. Ancak kompozit malzemelerin örneğin cam elyaf bazlı kompozitlerin elektrik iletkenliğinin oldukça az olması, uçak üzerine yıldırım düşmesi ve sürtünme etkisi ile oluşan statik elektrik akımının uçak yüzeyinden taşınmamasına ve uçağa zarar vermesine neden olmaktadır. Bu nedenle genellikle kompozit tabakanın üzerine veya değişik katmanlarına alüminyum tabaka yapıştııılarak elektrik iletkenliği sağlanmaya çalışılmaktadır. Farklı tür malzemelerin yapıştırılma tekniği, malzemelerin mekanik, kimyasal ve fiziksel özelliklerine göre değiştiğinden uygun yapıştırıcının tespit edilmesi önem arz etmektedir. Bu çalışmada, cam elyaf kompozit malzemelerin alüminyum plaka ile yapışmasında kullanılan farklı yapıştıııcıların yapışma mekanik özelliklerine etkisi deneysel olarak incelenmiștir.

Anahtar Kelimeler: Alüminyum-Kompozit yapıştırma, Cam elyaf kompozit

\section{Adhesive Bonding of Aluminium Plate to Glass Fibre Composites and Investigation of its Mechanical Properties}

\begin{abstract}
Especially in the aviation industry, using of composite materials has gradually increased to improve the energy efficiency and to reduce the weight. However, since the composite materials such as glass fiber based composites have very few of the electrical conductivity, it causes lightning strikes on aircraft, nonmoving of static electricity (due to the friction effect)over the surface of aircraft and cause damage on aircraft. Therefore, it is usually tried to be glued aluminium layer to different layers of the composite layers for obtaining electrical conductivity. Bonding technique of dissimilar materials is changing according to mechanical, chemical and physical properties of the materials. Therefore, determining of the proper adhesive is important. In this paper, the effect of different adhesives, which are used for bonding of glass fibre composite with aluminium plates, on the mechanical properties have been experimentally investigated.
\end{abstract}

Keywords: Aluminium-Composite bonding, Glass fibre composite

\footnotetext{
* Sorumlu yazar (Corresponding author) : M. Veysel ÇAKIR, Gaziantep Üniversitesi, Havacllk ve Uzay Bilimleri Fakültesi, Uçak ve Uzay Mühendisliği Bölümü, Gaziantep.cakir@gantep.edu.tr
} 


\section{GİRIŞ}

Kompozit malzemeler havacilık ve otomotiv endüstrisinde yaygın olmasının yanı sıra inşaat ve gemi mühendisliği alanlarında da kullanılmaktadır. Birçok uygulamada tek bir gövde halinde bütün yapıyı tamamlamak neredeyse imkânsızdır. Bu bağlamda, farklı parçaların birleştirilmesi büyük önem arz etmektedir.

Kompozit ve metal malzemelerin birleştirilmesinde yaygın olarak cıvata veya perçin kullanılır. Bunların montaj ve demontaj işlemleri oldukça kolay yapılabilmektedir. Fakat bu tür uygulamalar kompozit malzemeler üzerinde uygulandığı zaman birleştirme noktalarındaki deliklerde mikro veya makro tahribatlar oluşabilmektedir. Dolayısıyla yapıştırma bağlantılarının cıvata ve perçine göre avantajları bulunmakta ve bu birleştirmelere alternatif olarak kullanımları artmaktadır.

Yapıştırıcılar basit anlamda, doğal veya sentetik olmak üzere yüzey ya da kimyasal bağları kullanarak malzemeleri yapıştıran akışkan veya yarı akışkan sıvılardır. Yapışma işlemi ise temelde iki yüzey arasında atomik ve moleküler etkileşim sonucu meydana gelir [1].

Kullanılan yapıştırıcı tipine, bağlantı tasarımına, uygulama metoduna ve son sistemin amaçlanan işlevine bağlı olarak yapıştırıcı ile birleştirme bir veya daha fazla avantajlar sunabilir. Bunlar;

- Bileşim, genleşme katsayısı, elastik modülü ve kalınlık gibi özellikler bakımından farklılık arz eden değişik tip malzemeleri birleştirme kabiliyetleri

- Civata, perçin gibi bağlama elemanlarınca sebep olunan düzensiz yüzey hatlarının yapıştırıcı ile birleştirme durumunda ortadan kaldırılarak son sistemin görüntüsünde daimi bir iyileşme sağlanabilir

- Cıvata, perçin gibi bağlama elemanları ve nokta kaynağından dolayı küçük temas alanlarında ortaya çıkan küçük gerilme yığılmalarının azalması ile tüm yapışma alanı boyunca daha düzenli bir gerilme dağılımı elde edilebilir

- Fretting (Birbiri üzerinde çalışan parçaların mikro hareketi sonucu oluşur) korozyonunu önler

- Farklı iki malzemenin birleşmesi sonucu oluşabilecek galvaniz korozyonu önler

- Gerilmeleri absorbe edebilme, uniform dağılabilme veya iletebilmeleri sayesinde birçok yapıştırıcının yapışma bağları dinamik darbelere karşı daha yüksek dayanım ve gerilip uzama kabiliyeti sağlar. Bu sayede yorulma dayanımı iyileşir ve titreşimlere direnebilme ve esneklik özellikleri artar (Şekil 1)

- Daha hassas rijit bağlantılar elde edilebilinir

- Konstrüksiyonel bir bütünlük düşünüldügünde kaynaklı ve perçinli bağlantılara nazaran hafiflik sağlar

- Küçük kuvvet ve momentlerin üretilmesinde talaşlı imalat ücretlerini azaltır, daha az malzeme kullanılabilinir ve daha yüksek toleranslarla çalışılabilinir [2, 3].
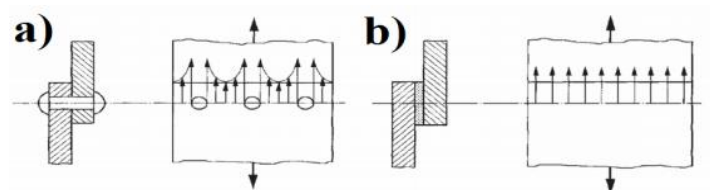

Şekil 1. Perçin (a) ve yapıştırma bağlantısında, (b) kuvvet iletimi [2]

Yapıştırma bağlantılarının bu avantajları ile birlikte, kolay taşınabilirlik, az yer kaplama ve birbirinden farklı bileşenleri bir araya getirme gibi faydaları da bulunmaktadır. Yapıştırma işlemlerinin kolayca otomatik hale getirilebilir olması bu metotla birleştirme yöntemlerinin uygun ve düşük maliyetli olmasını da sağlar. Geleneksel birleştirme yöntemlerine göre uygulamadaki kolaylığı, düşük maliyeti ve hafifliğinden dolayı kompozit malzemelerin birleştirilmesinde yaygınlaşmıştır. Ayrıca gerilme yığılmalarını giderdiği (Şekil 1), korozyona karşı dayanıklı ve yorulma ömrü uzun olduğu için kompozit malzemelerde meydana gelen hasarın tamirinde de tercih edilmektedir. Bu nedenle, otomotiv ve özellikle havacılık sektöründe sıkça kullanılmaktadır [4, 5, 6]. Uçak konstrüksiyonların da kullanılan ve yapıştırıcı kullanılarak imal edilen 
yapılar Şekil 2'de görülmektedir. Uçağın yan duvarları ve kaplamada kullanılan petek dokulu yapılar genellikle alüminyum olan plakalar ile yapıştırıcılar aracılığıyla birleştirilmektedir [7].

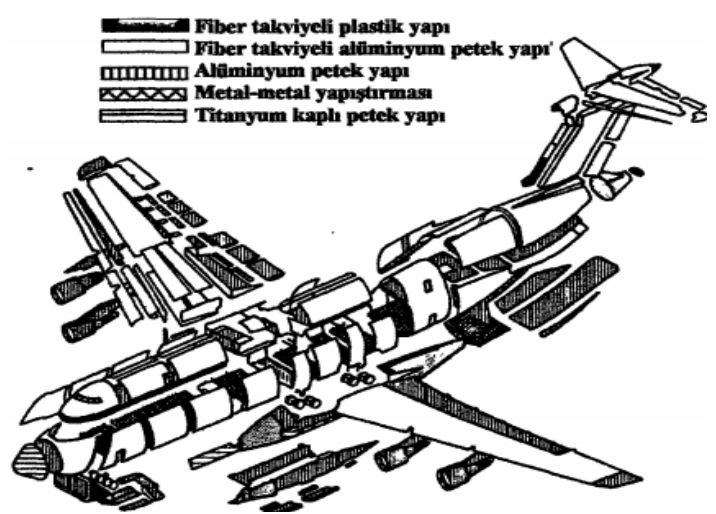

Şekil 2. Lockheed C-5A uçağında yapıştırıcıların kullanıldığı alanlar [8]

Yapıştırıcılar ile ilgili yapılan çalışmalarda, Adams ve Comyn [9] yapıştırma bağlantılarının önemini vurgulayarak, diğer birleştirme tekniklerine bir alternatif olduğu, özellikle kompozit malzemelerin yapıştırılmasında, uygun yüzey işlemi ve uygun yapıştırıcı seçiminin yapılması gerektiğini belirtmiştir.

Lees [10], yapıştırma işleminde dikkat edilecek hususların; yapıştırıcının kimyası, yapıştırıcı kullanmanın avantaj ve dezavantajları, bindirme bağlantılarındaki bindirme uzunluğu, yapıştırılan malzeme kalınlığının etkisi ve uygun yükleme şekillerinin belirlenmesi olduğunu belirtmiş ve en çok kullanılan mühendislik malzemelerinin yüzey hazırlama metodları üzerinde durmuştur.

Kinloch [11], yapıştırıcıların kullanımındaki gelişmeleri göstermiş, otomotiv ve uçak sanayisinde kompozit malzeme yapımında kullanımları üzerinde durmuştur. Yapıştırıcıların kullanma nedenleri ve kullanımlarını kısıtlayan faktörler ve konstrüktif olarak dikkat edilmesi gereken kurallar, adhezyon, kohezyon ve curing (sertleşme) olaylarını açıklamaya çalışmıştır. Ayrica yine Kinloch [12] tarafindan hazırlanan "Adhezyon ve Yapıştırıcılar" adlı yayında adhezyon olayının açıklanmasında kullanılan teoriler incelenilerek, adhezyon olayını tek bir teori ile açıklamanın yeterli olmadığı sonucuna varılmış, teorilerden birkaçının bir araya gelmesi ile açıklanabileceğini belirtilmiştir. Yapışma yüzeyinin hazırlanması ve yapıştırıcıların sertleşme mekanizmaları hakkında bilgiler verilmiş ve yapışma bağlantılarının mekanik davranışları ve kırılma mekaniği hakkında açıklamalar yapılmıştır.

Bunların yanı sıra, Gediktaş [13] yapıştırma bağlantısının iyi olabilmesi için yüzeylerin uygun şekilde hazırlanması gerektiğini, bir yapıştırma bağlantısında adhezyon kuvvetleri ve yüzey pürüzlülüğünün kuvvet iletiminde en etkili olan faktörler olduğunu belirtmiştir. Yapıştırıcının pürüzler arasına girip sertleşmesi ile bir şekil bağ1 meydana geldiği bu sebepten yapıştırılacak olan yüzeylerin çok düzgün olmaması gerektiği ve yüzeylerin pürüzlendirilmesi gerektiği bu işlemin de zımpara ile yapılabileceği vurgulanmıştır ve yüzeyin zımpara izleri çeşitli yönlerde olacak şekilde hazırlanmasının gereği üzerinde durulmuştur.

Bu çalışmada, cam elyaf kompozit malzemelerin yeni nesil yapıştırıcılar (Araldite 2014-1 ve Carbonkleber CG-49) kullanılarak, elektrik iletkenliği yüksek olan dövme alüminyum alaşımı 1050-A plaka ile cam elyaf kompozitin tek bindirmeli yapıştırılarak, yapışma mekanik özelliklerine etkisi deneysel olarak incelenmiştir.

\section{DENEYSEL ÇALIŞMA}

Yapılan deneysel çalışmalarda cam elyaf kompozit ve alüminyum plakalardan belirlenen ölçülere göre numuneler çıkarılmış, numune yüzeyleri zımparalanarak pürüzlülük uygun hale getirilmiş ve yüzeyler temizlenmiş, yapıştırma işlemi uygulanmış, yapıştırma ile birleştirilmiş numuneler çekme deneyine tabi tutulmuştur.

\subsection{Malzeme Özellikleri}

Deneysel çalışmada elektrik iletkenliği yüksek (61\% IACS) 1050 Alüminyum $(0,4 \mathrm{Fe}, 0,25 \mathrm{Si}$, $0,07 \mathrm{Zn}, 0,05 \mathrm{Ti}, 0,05 \mathrm{Mg}, 0,05 \mathrm{Mn}, 0,05 \mathrm{Cu})$ ve cam elyaf epoksi reçine matris kompozit plakalar sirasiyla $400 \times 200 \times 2 \mathrm{~mm}$ ve $350 \times 150 \times 2 \mathrm{~mm}$ 
ölçülerinde ticari olarak satın alınmıştır [14, 15]. Yapıştırma yüzeylerinin hazırıı̆ı için Nikon marka 400-C silikon karbit zımpara, yüzey temizliği için ise saf aseton temin edilmiştir. Yapıştırma işlemi için Carbonkleber CG-49 ve Araldite 2014-1 isimli ticari epoksi türü yapıştırıcılar kullanılmıştır.

\subsection{Numune Hazırlığı}

Alüminyum ve cam elyaf kompozit plakalar giyotin ile kesilerek $100 \times 25 \times 2 \mathrm{~mm}$ boyutlarına getirilmiştir (Şekil 3).

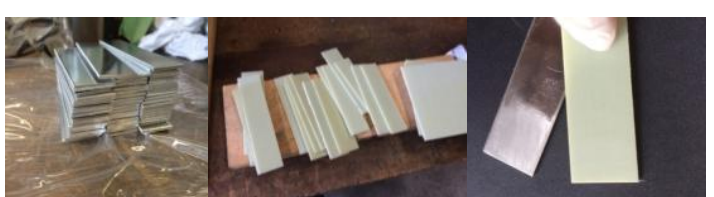

Şekil 3. Alüminyum ve cam elyaf kompozit numuneler

\subsection{Metot}

Yapıştırma bağlantılarında yapıştırıcı alan yüzeylerinin çok parlak olmaması gerektiği, çok parlak olan yerlerde pürüzlülügün kama etkisinin ortadan kalktığ 1 ve yüzey pürüzlülüğünün $\mathrm{Ra}=0,8-3,2 \mu \mathrm{m}$ aralığında olması gerektiği belirlenmiştir [3]. Bu bilgiler 1şığında, Şekil 4-b'de gösterilmiş olan yapıştırıcının uygulanacağı bölge ( $b=$ bindirme uzunluğu), farklı bindirme $(15,20$, $25,30 \mathrm{~mm}$ ) uzunluklarına göre giyotin ile kesildikten sonra, 400 Grid zimpara ile zımparalanıp yapıştırılmaya uygun hale getirilmiştir (Şekil 4-a).
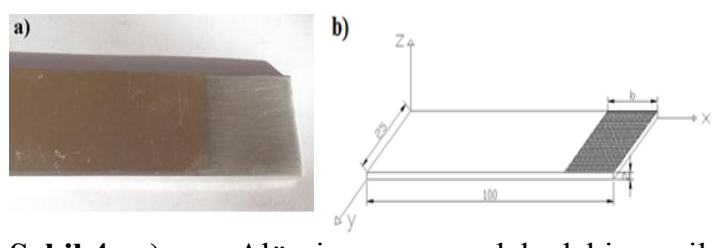

Şekil 4. a) Alüminyum plakadaki ile zımparalanmış bölge, b) Plaka boyutu $(100 \times 25 \times 2 \mathrm{~mm})$

Numunelerin yüzeyleri saf aseton yardımı ile temizlenip yağdan ve kirden arındırılmış (Şekil 5-a), yapıştırmanın uygulanması için
0,2 mm kalınlığında basit bir levha kullanılmıștır (Şekil 5-b). Yapıştırıcıların sertleştirici ve epoksi reçineleri $1 / 2$ oranda karıştırılarak yapıştırmaya hazırlanmıştır. Yapıştırıcı tabakası 0,2 $\mathrm{mm}$ kalınlığında olacak şekilde, farklı bindirme uzunluklarına göre numunelere uygulanmıştır (Şekil 6).

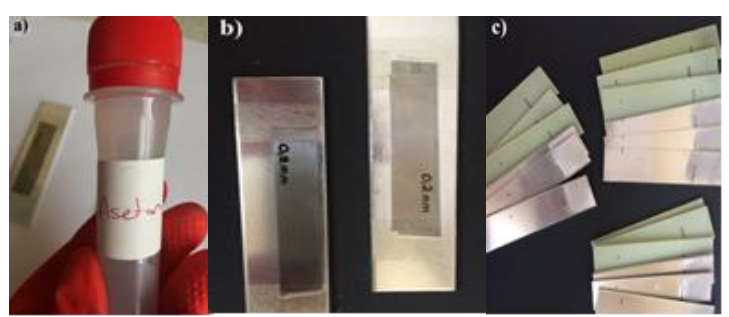

Şekil 5. a) Yüzey temizliğinde kullanılan aseton, b) Yapıştırma kalınlığını ayarlamak için $\begin{array}{llll}\text { kullanilan } & 0.2 \mathrm{~mm} & \mathrm{~m} & \mathrm{~m} \text { levha, }\end{array}$ c) Ölçülendirilmiş ve uygulamaya hazır numuneler

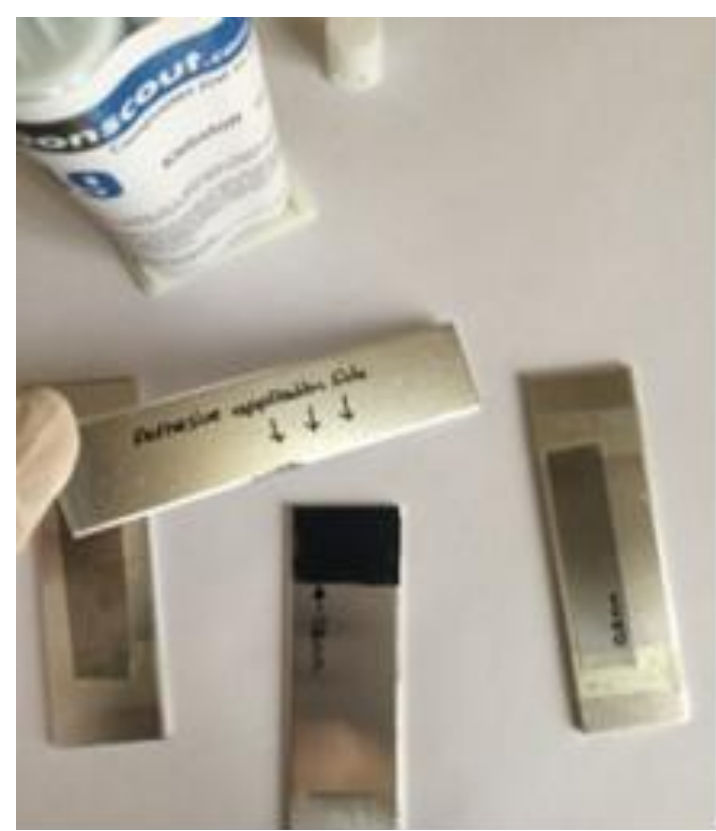

Şekil 6. Yapıştırıcı uygulama

Çizelge 1'de mekanik özellikleri verilen yapıştırıcılardan Carbonkleber CG-49 uygulanan numuneler yedi günlük, Araldite 2014-1 uygulanan numuneler bir günlük kuruma süreci oda sicaklığında $\left(23 \mathrm{C}^{\circ}\right)$ tamamlanmıştır. 
Çizelge 1. Deneysel çalışmalarda kullanılan yapıştırıcıların mekanik özellikleri

\begin{tabular}{|l|c|c|}
\hline Özellikler & $\begin{array}{c}\text { Araldite } \\
2014\end{array}$ & $\begin{array}{c}\text { CG-49 } \\
\text { Carbonkleber }\end{array}$ \\
\hline $\begin{array}{l}\text { Sertleştirici-Epoksi } \\
\text { Reçine oranı }\end{array}$ & $1 / 2$ & $1 / 2$ \\
\hline Renk & $\begin{array}{c}\text { Koyu } \\
\text { Gri }\end{array}$ & Siyah \\
\hline $\begin{array}{l}\text { Kuruma Süresi } \\
\left(23 \mathrm{C}^{\circ}\right)\end{array}$ & $\begin{array}{c}40 \\
\text { dakika }\end{array}$ & 7 gün \\
\hline Viskozite & $\begin{array}{c}100 \\
\mathrm{MPa} . \mathrm{s}\end{array}$ & $300 \mathrm{MPa} . \mathrm{s}$ \\
\hline $\begin{array}{l}\text { Gerilme } \\
\text { Dayanımları }\end{array}$ & $19 \mathrm{MPa}$ & $26 \mathrm{MPa}$ \\
\hline Kesme Modülü & $4 \mathrm{MPa}$ & $5 \mathrm{MPa}$ \\
\hline
\end{tabular}

Sonrasında numuneler, burkulma kuvvetlerini minimize etmek amacıyla çekme deneyi yapılacak cihazın kavrama çeneleri kısmı için her iki ucundan $25 \times 25 \mathrm{~mm}$ ölçülerinde olan cam elyaf kompozitler ile yapıştırılarak deney mekanizmasına hazır hale getirilmiştir (Şekil 7-8).

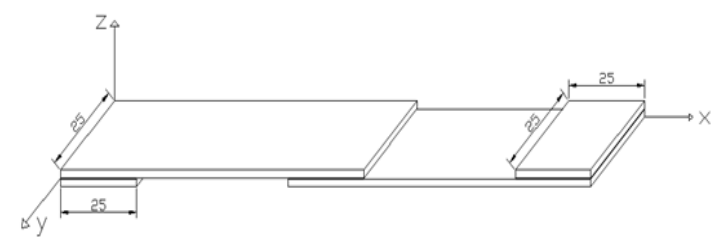

Şekil 7. $25 \times 25 \mathrm{~mm}$ ölçülerindeki kompozitlerin numuneler üzerinde gösterilmesi

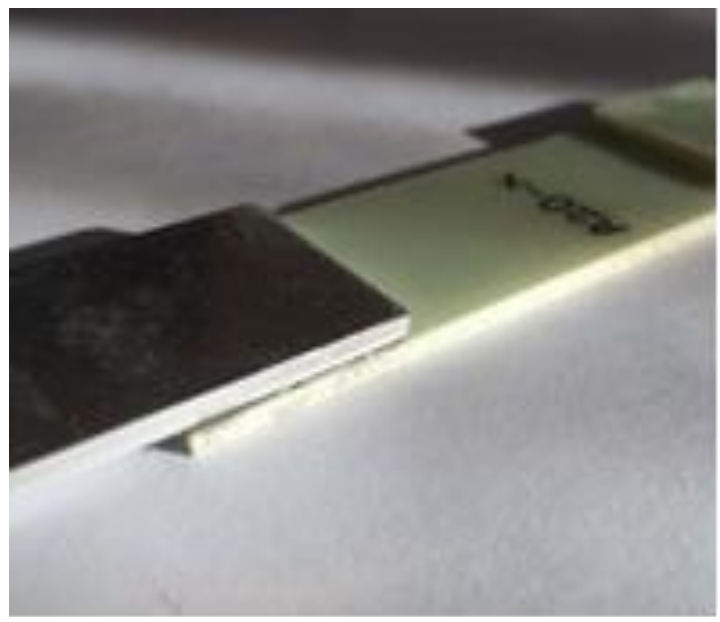

Şekil 8. Çekme deneyine hazır numune
Numune isimleri; yapıştırıcı ismi ve bindirme mesafelerine göre belirlenmiştir. Carbonkleber CG-49 ve Araldite 2014-1 yapıştırıcıları ile 15, 20, 25, $30 \mathrm{~mm}$ bindirme uzunluklarına göre üçer adet olarak toplam 24 adet numune hazırlanmıştır (Şekil 9). Numunelerin kodlanması Çizelge 2'de verilmiştir

Çizelge 2. Numunelerin bindirme uzunluğu ve yapıştırıcı tipine göre kodlandırılması

\begin{tabular}{|c|c|c|}
\hline $\begin{array}{c}\text { Numune } \\
\text { Kodu }\end{array}$ & $\begin{array}{c}\text { Bindirme } \\
\text { Uzunluğu } \\
(\mathrm{mm})\end{array}$ & Yapıştırıcı Türü \\
\hline C15 & 15 & Carbonkleber CG-49 \\
\hline C20 & 20 & Carbonkleber CG-49 \\
\hline C25 & 25 & Carbonkleber CG-49 \\
\hline C30 & 30 & Carbonkleber CG-49 \\
\hline A15 & 15 & Araldite 2014-1 \\
\hline A20 & 20 & Araldite 2014-1 \\
\hline A25 & 25 & Araldite 2014-1 \\
\hline A30 & 30 & Araldite 2014-1 \\
\hline
\end{tabular}

\section{4. Çekme Deneyleri}

Numuneler ASTM D 3039 standartlarında 300 kN kapasiteli Shimadzu AG-X (Şekil 10-a) universal test makinesi ile eksenel çekme deneyine tabi tutulmuştur. Numuneler, $1 \mathrm{~mm} / \mathrm{dak}$ ilerleme hızında test edilmiştir. Deneyler oda sıcaklığında gerçekleştirilip, sonuçlar için ortalama değerler alınmıştır.

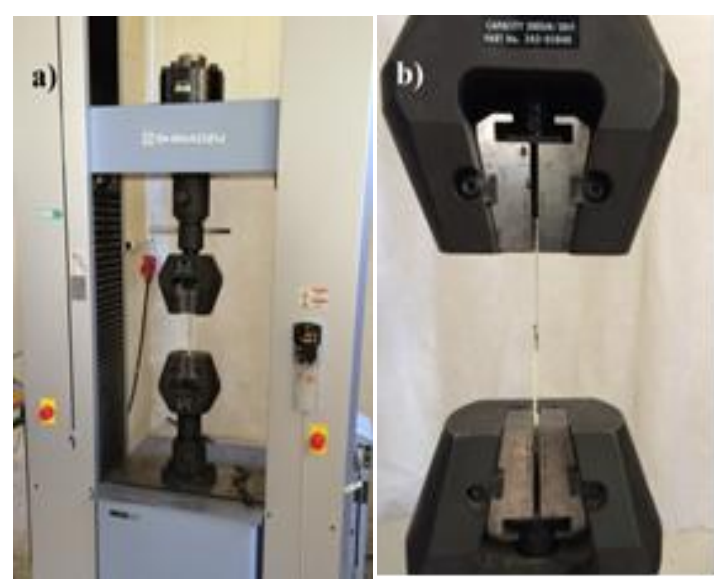

Şekil 10. (a) Shimadzu AG-X çekme test cihazı, (b) Örnek bağlama şekli 


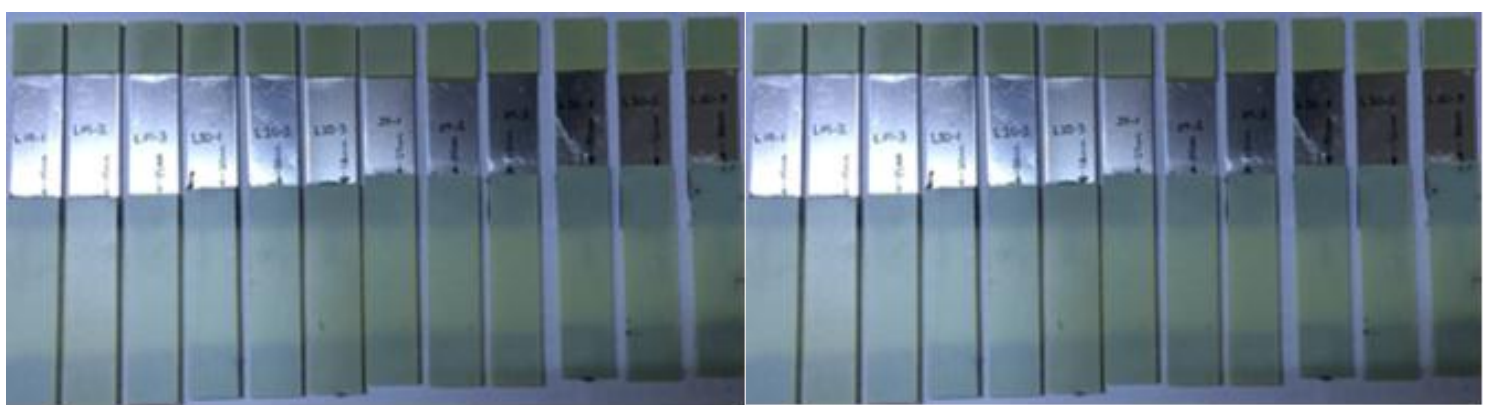

Şekil 9. Farklı bindirme uzunluklarında yapıştırılmış numuneler

\section{DENEY SONUÇLARI VE DEĞERLENDİRME}

Yapıştırma ile birleştirilen numuneler çekme kuvveti uygulandiktan sonra, maksimum çekme kuvvetine göre kesme mukavemeti, denklem 1 ile hesaplanmıştır.

$\tau=\frac{F}{w * b}$

Denklemdeki F kopma yükünü, w yapışma genişliğini, b ise bindirme uzunluğunu göstermektedir. Uygulanan mekanik testlerin sonuçları Çizelge 3'te ve Şekil 11-12'de görülmektedir.

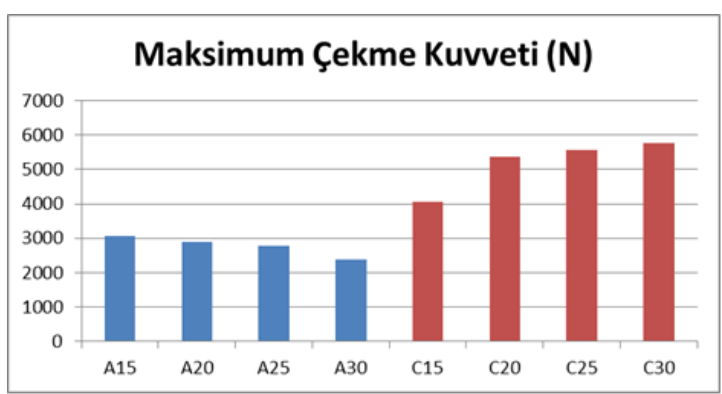

Şekil 11. Çekme testi sonucu numunelere uygulanan yük değerleri grafiği

Araldite 2014-1 isimli yapıştırıcı ile yapılan deneylerde bindirme mesafesi $15 \mathrm{~mm}$ olan numune değerlerinin ortalamaları göz önünde bulundurulduğunda daha fazla yüke dayandıkları kaydedilip, bindirme mesafesi artan numunelerde bu oranın azaldığı gözlemlenmektedir (Şekil 11). Araldite 2014-1 yapıştırıcıdaki 15 mm'lik bindirme uzunluğundaki maksimum çekme kuvveti $20 \mathrm{~mm}, 25 \mathrm{~mm}$ ve $30 \mathrm{~mm}$ bindirme mesafesine göre sirasiyla $\% 6, \% 10$ ve $\% 29$ oranlarında yüksek görülmektedir. Çekme mukavemetleri (Şekil 12) ise $15 \mathrm{~mm}$ 'lik bindirme uzunluğunun diğer bindirme uzunluklarına göre $\% 42, \% 83$ ve $\% 159$ oranlarında yüksek olduğu elde edilmiştir.

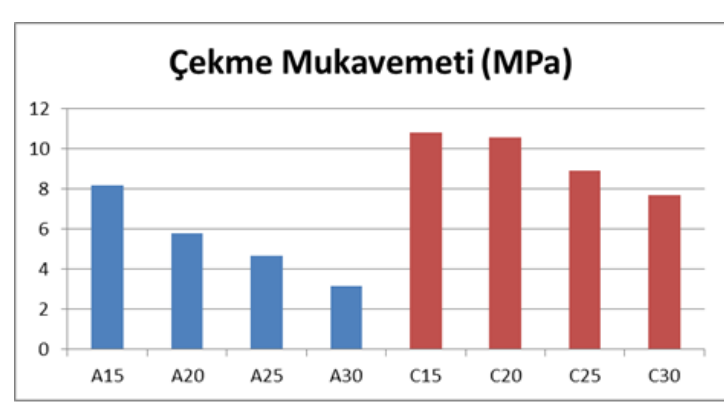

Şekil 12. Yapıştırılmış numunelerin kesme mukavemetlerinin karşılaştırılması

Carbonkleber CG-49 isimli yapıştırıcı ile yapıştırılan $\mathrm{C}$ serisi numunelerin bindirme mesafesi arttıkça daha fazla yüke dayandıkları görülmektedir. $\mathrm{Bu}$ artış kademeli olarak yükselmekte ve en fazla uygulanan yük C30 serisi numunelerde gözlenmektedir. Buna göre maksimum C30 numunesindeki maksimum çekme kuvveti, C25, C20 ve C15 numunelerdeki maksimum çekme kuvvetine göre sırasıyla \%3, \%7 ve $\% 42$ artış göstermektedir. Ancak çekme mukavemeti C15 numunesinde en yüksek olmakla birlikte $\mathrm{C} 20, \mathrm{C} 25$ ve $\mathrm{C} 30$ numunelerine göre sirasıyla $\% 0,5, \% 21$ ve $\% 40$ oranlarında yüksek olduğu görülmektedir. İki farklı yapıştırıcının maksimum çekme kuvvetleri karşılaştırıldığında 
C30 serisi numunelerdeki maksimum kuvvet A15 serisi numunelerdeki kuvvetten \%87 fazla olduğu, çekme mukavemetleri kıyaslandığında ise, C15 numunedeki çekme mukavemeti A15 numunedeki çekme mukavemetine göre \%32 fazla olduğu tespit edilmiştir. Yapıştırma alanının, bağlantı mukavemeti üzerine etkisini araştırmak için yapılan deneysel bir çalışmada [16] yapıştırma alanı arttırıldığında bağlantının Şekil 12'de görüldüğü gibi çekme mukavemetinin önemli bir oranda azaldığı gözlemlenmiştir, bu olay deformasyon direncinin alan büyüdükçe azalmasından kaynaklanmaktadır. Buna göre Şekil 12 'de görüldüğü üzere A15 ve C15 numunelerinde maksimum çekme gerilmesi elde edilmiştir. C20-1, C30-1, C30-3 numuneleri deneyinde uygulanan çekme kuvvetleri 5438,63 N, 5712,46 N, 5760,91 N'da iken kopmanın yapıştırıcıdan değil, numuneden (alüminyumdan) olduğu görülmüştür (Şekil 13-20). Dolayısıyla, bu test için malzemeler arası yapıştırma mukavemetinin numune mukavemetinden yüksek olduğu da söylenebilir.

Çizelge 3. Çekme testi sonuçları

\begin{tabular}{|c|c|c|c|c|c|}
\hline $\begin{array}{l}\text { Dene } \\
\text { y No }\end{array}$ & Yapıştırıcı & Numune & $\begin{array}{c}\text { Maksimum } \\
\text { Çekme Kuvveti } \\
(\mathbf{N}) \\
\end{array}$ & $\begin{array}{c}\text { Maksimum } \\
\text { Deformasyon } \\
(\mathbf{m m}) \\
\end{array}$ & $\begin{array}{c}\text { Çekme } \\
\text { Mukavemeti } \\
\text { (MPa) } \\
\end{array}$ \\
\hline 1 & Araldite & A15-1 & 3300,01 & 1,82 & 8,80 \\
\hline 2 & Araldite & A15-2 & 3001,55 & 1,76 & 8,00 \\
\hline 3 & Araldite & A $15-3$ & 2923,96 & 1,55 & 7,80 \\
\hline 4 & Araldite & A20-1 & 2751,02 & 1,63 & 5,50 \\
\hline 5 & Araldite & A20-2 & 3065,35 & 1,80 & 6,13 \\
\hline 6 & Araldite & A20-3 & 2851,55 & 1,45 & 5,70 \\
\hline 7 & Araldite & A25-1 & 2701,40 & 1,50 & 4,32 \\
\hline 8 & Araldite & A25-2 & 2854,44 & 1,54 & 4,57 \\
\hline 9 & Araldite & A $25-3$ & 2824,02 & 1,32 & 4,52 \\
\hline 10 & Araldite & A30-1 & 2511,84 & 1,27 & 3,35 \\
\hline 11 & Araldite & A30-2 & 2394,30 & 1,70 & 3,19 \\
\hline 12 & Araldite & A30-3 & 2202,54 & 1,34 & 2,94 \\
\hline 13 & Carbonkleber CG49 & $\mathrm{C} 15-1$ & 4032,37 & 2,83 & 10,75 \\
\hline 14 & Carbonkleber CG50 & $\mathrm{C} 15-2$ & 4115,95 & 3,86 & 10,98 \\
\hline 15 & Carbonkleber CG51 & $\mathrm{C} 15-3$ & 3999,09 & 2,29 & 10,66 \\
\hline 16 & Carbonkleber CG52 & C20-1 & 5438,63 & 3,42 & 10,88 \\
\hline 17 & Carbonkleber CG53 & $\mathrm{C} 20-2$ & 5462,84 & 3,23 & 10,93 \\
\hline 18 & Carbonkleber CG54 & $\mathrm{C} 20-3$ & 5216,85 & 1,64 & 10,43 \\
\hline 19 & Carbonkleber CG55 & $\mathrm{C} 25-1$ & 5478,38 & 1,46 & 8,77 \\
\hline 20 & Carbonkleber CG56 & $\mathrm{C} 25-2$ & 5650,73 & 2,89 & 9,04 \\
\hline 21 & Carbonkleber CG56 & $\mathrm{C} 25-3$ & 5549,55 & 3,56 & 8,88 \\
\hline 22 & Carbonkleber CG58 & C30-1 & 5712,46 & 4,42 & 7,62 \\
\hline 23 & Carbonkleber CG59 & C $30-2$ & 5813,65 & 4,58 & 7,75 \\
\hline 24 & Carbonkleber CG60 & C30-3 & 5760,91 & 4,85 & 7,68 \\
\hline
\end{tabular}




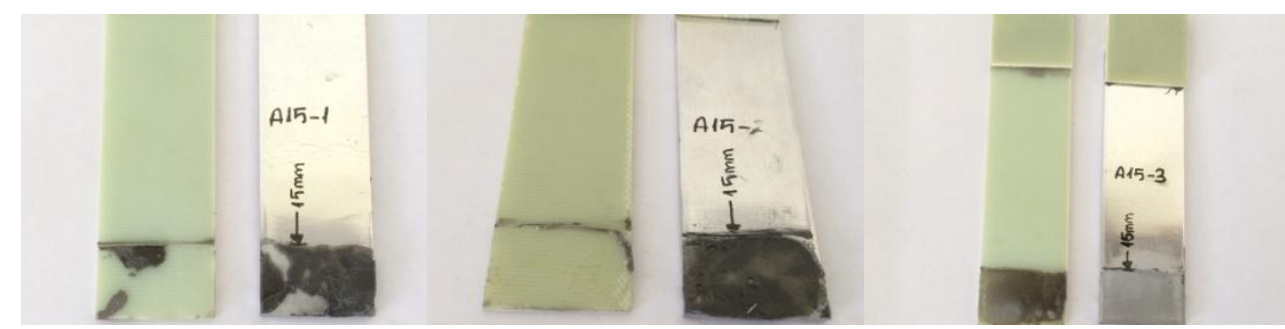

Şekil 13. Kesme deneyi sonrası A15 numuneleri

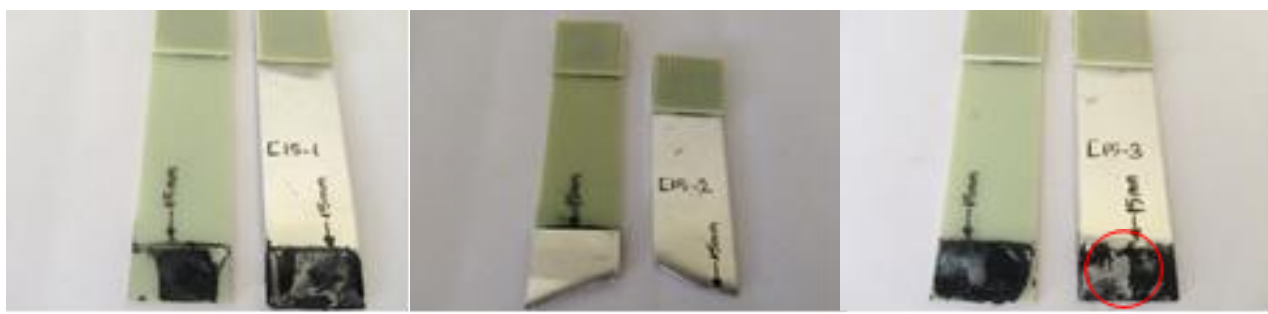

Şekil 14. Kesme deneyi sonrası C15 numuneleri

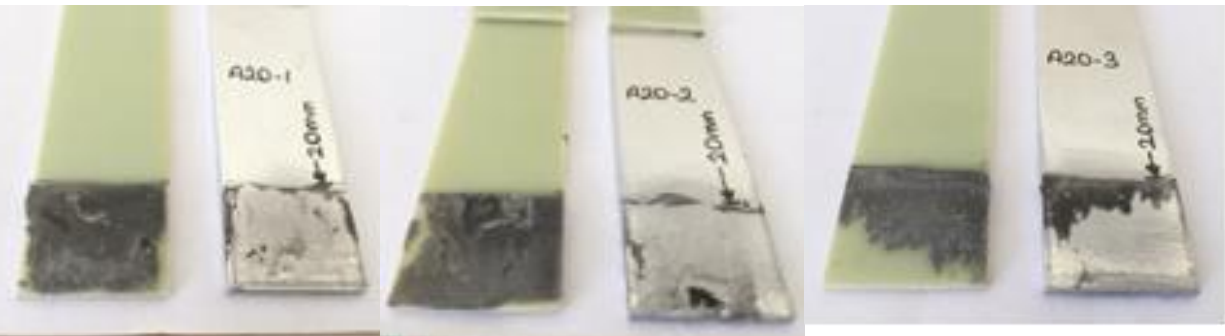

Şekil 15. Kesme deneyi sonrası A20 numuneleri

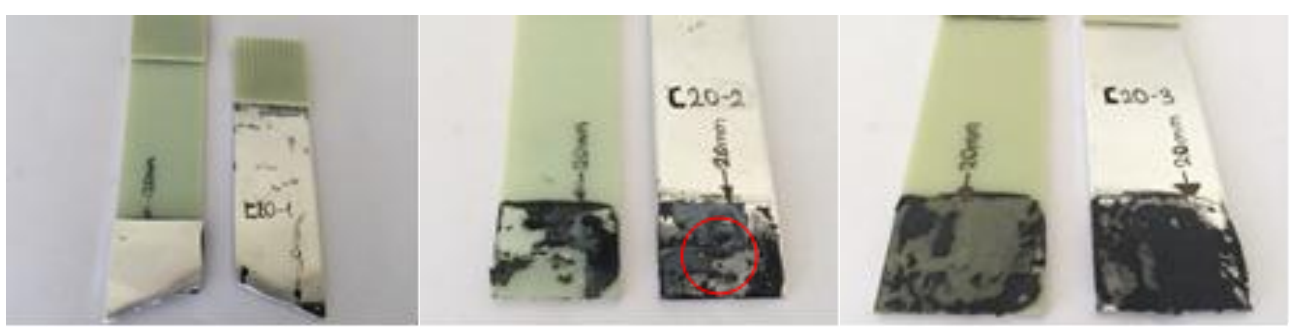

Şekil 16. Kesme deneyi sonrası C20 numuneleri

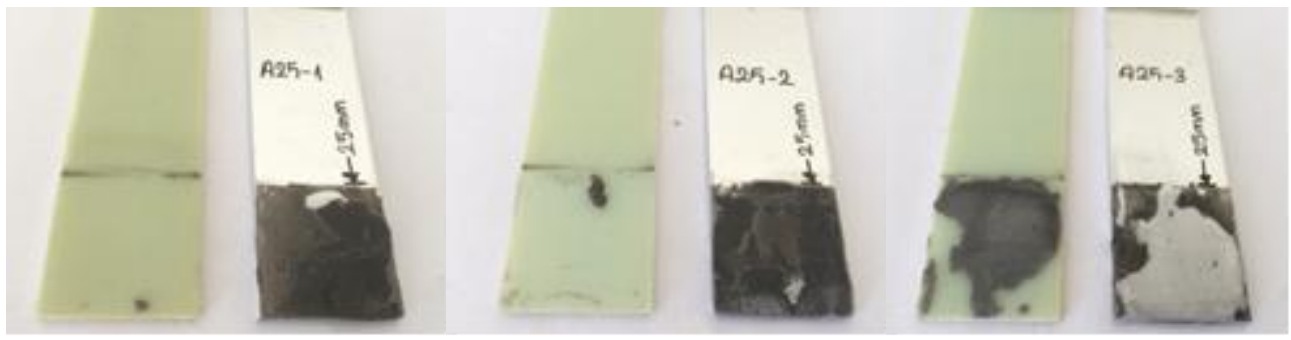

Şekil 17. Kesme deneyi sonrası A25 numuneleri 


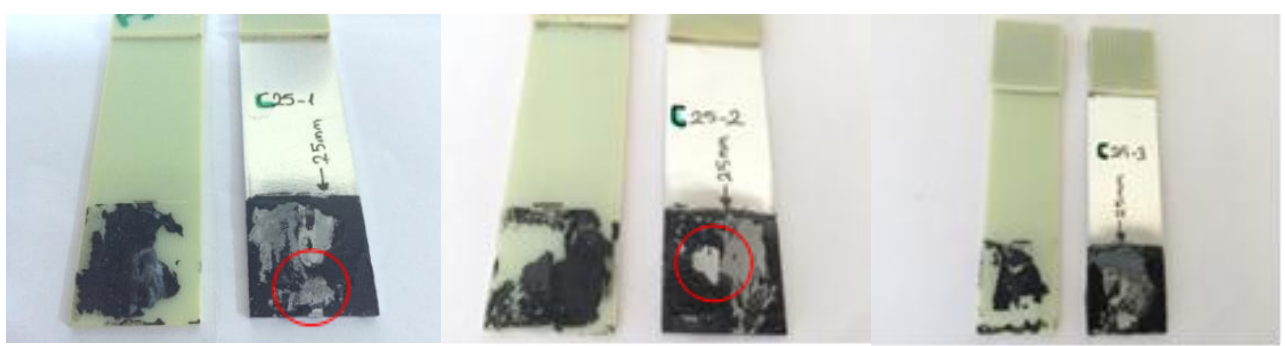

Şekil 18. Kesme deneyi sonrası C25 numuneleri
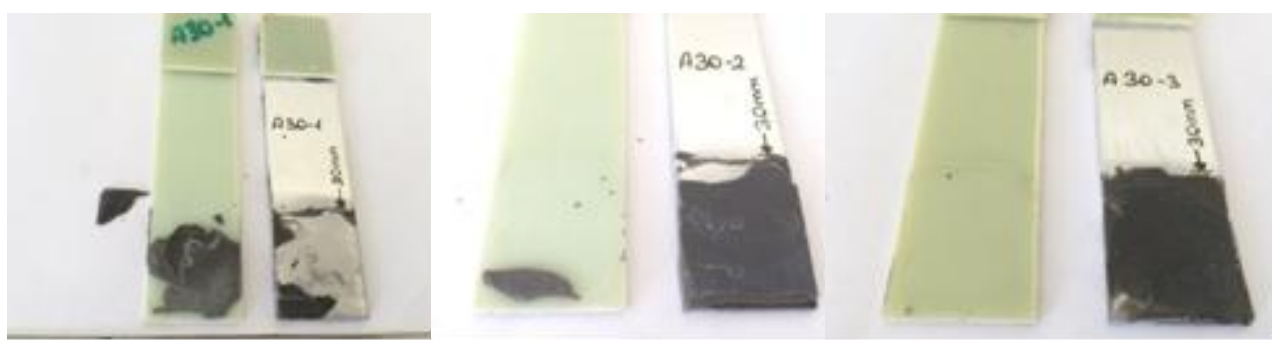

Şekil 19. Kesme deneyi sonrası A30 numuneleri

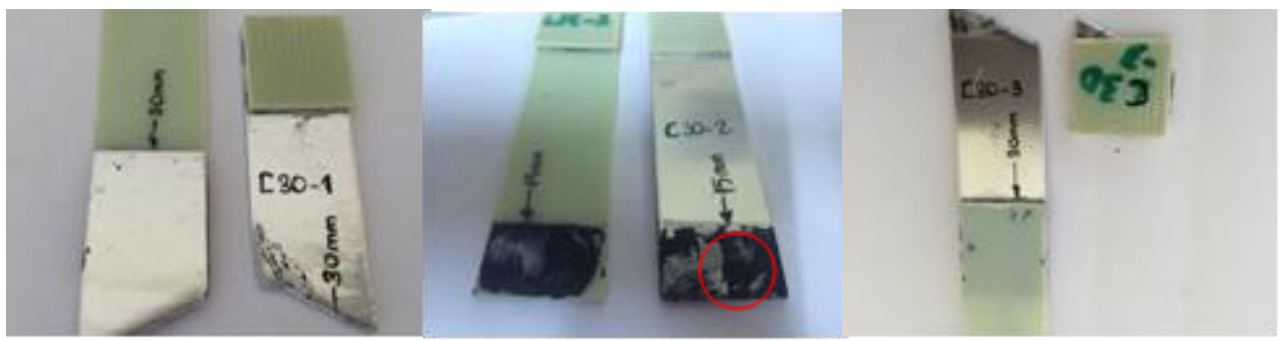

Şekil 20. Kesme deneyi sonrası C30 numuneleri

\section{SONUÇLAR}

Yapılan bu çalışmada alüminyum ve cam elyaf plaka plakaların yeni nesil yapıştırıcılar ile yapıştırılabilme kabiliyetlerinin incelenebilmesi için tek bindirmeli yapıştırma metodu uygulanmıştır. Deneylerde tutarlılığın gözlenebilmesi için her bindirme mesafesinde üçer numune ile çalışılmıştır. Hazırlanan tüm numunelere çekme deneyi uygulanmış ve sonuçlar değerlendirilmiştir. Yapılan deney sonuçlarına göre;

- Alüminyum ve cam elyaf kompozitin yapışma dayanımlarının daha yüksek olabilmesi için yapıştırma öncesi yüzeylerinin yeterli bir biçimde hazırlanması gerekmektedir.
- Numunelerin hasar sonrası fotoğraflarında yapışma yüzeyleri incelendiğinde Araldite 2014-1 ile yapıştırılan plakalarda tam yapıştırma olmadığı, yapıştırıcının neredeyse tamamının tek bir yüzeyde kaldığ görülmektedir. Karbonkleber CG-49'un ise numunelerde her iki yüzeye yapıştığı, numunelerin çoğunda kompozit yüzeyden parçalar kopardığı görülmüştür.

- Araldite 2014-1 isimli yapıştırıcı ile yapılan deneylerde $15 \mathrm{~mm}$ bindirme mesafeli olan numunelerin daha fazla yüke dayandığı ve bindirme mesafesi arttıkça bu oranın azaldığı gözlemlenmiştir. Yine bu yapıştırıcının uygulandığı $15 \mathrm{~mm}$ bindirme mesafeli numunelerde maksimum kesme mukavemeti görülürken, bindirme mesafesi arttıkça bu 
oranın \%42, \%89 ve \%159 oranlarında azaldığ gözlemlenmiştir.

- Maksimum kuvvet, Araldite 2014-1 yapıştırıcısının uygulandığı $15 \mathrm{~mm}$ bindirme mesafeli numunelerde görülürken, Karbonkleber CG-49 isimli yapıştırıcının uygulandığ $30 \mathrm{~mm}$ bindirme mesafeli numunelerde görülmüştür.

- Karbonkleber CG-49 isimli yapıştırıcı ile hazırlanan numunelerin bindirme mesafesi arttıkça daha fazla yüke dayandıkları, en yüksek yük dayanımının C-30 serisi numunelerde olduğu görülmüştür. Çekme mukavemeti ise en yüksek C15 serisinde gözlemlenirken, çekme mukavemetinin bindirme mesafesi arttıça \%5, \%21, \%40 oranlarında arttığı gözlemlenmiştir.

- Yapıştırıcıların maksimum çekme kuvvetleri karşılaştığında Karbonkleber CG-49 uygulanan C30 serisindeki maksimum kuvvetin, Araldite 2014-1 uygulanan A15 serisindeki maksimum kuvvete oranla \%87 fazla olduğu gözlemlenmiştir. Yapıştırıcıların kayma mukavemetleri kıyaslandığında ise C15 serisindeki kayma mukavemetlerinin A15 serisindeki kayma mukavemetlerine oranla \%32 fazla olduğu gözlemlenmiştir.

- Yapıştırılan bazı numunelerdeki yapıştırma mukavemetinin numune mukavemetinden yüksek olduğu görülmüştür.

- Araldite 2014-1 ile Karbonkleber CG-49 tipi yapıştırıcıların kıyaslanmasında, Karbonkleber CG-49 tipi epoksi yapıştırıcı bağlantılarının daha yüksek mukavemetli olduğu belirlenmiştir.

\section{KAYNAKLAR}

1. Pukanszky, B., Fekete, E., 1999. Advanced polymer science 139 pp.53-109.

2. Loctite Corporation, 1995. Loctite Worlwide Design Handbook 1996/1997 Edition, pp. 463.

3. Loctite Corporation: Loctite Worlwide Design Handbook Second Edition. 1998. on CD.

4. Kinloch, A.J., Little M.S.G., Watts J.F., 2000. The role of the interphase in the environmental failure of adhesive joints. Acta Materiala. 48 (18-19): 4543-4553.

5. Yarrington, P., Zhang, J., Collier, C., Bednarcyk, B.A., 2005. Failure analysis of adhesively bonded composite joints. 46th AIAA/ ASME/ ASCE/ AHS/ ASC Structures, Structural Dynamics \& Materials Conference, Austin-Texas.

6. Papanikos, P., Tserpes, K.I., Pantelakis, S., 2007. Innovation and progression of composite patch debonding in adhesively repaired cracked metallic sheets. Composite structures. 81(2):303-311.

7. Wahab, M.M.A., 2012. Fatigue in Adhesively Bonded Joints. ISRN Materials Science. pp.5-16.

8. Engineered Materials Handbook, 1990. Adhesives and Sealants. Vol. 3. ASM International, USA.

9. Adams, R.D., Camyn, J., 2000. Joining Using Adhesives. Assembly Automation. 20(2):109117.

10. Lees, W.A., 1989. Adhesives and the Engineer. National Starch \& Chemical-Permabond Division Mechanical Engineering Publications, Vol. 1. London.

11. Kinloch, A.J., 1997. Adhesives in Engineering, Proceedings of the Institution of Mechanical Engineers. Part G: Journal of Aerospace Engineering. 211:307-335.

12. Kinloch, A.J., 1986. Adhesion and Adhesives Science and Technology. Vol. 1, Champman and Hall, London.

13. Gediktaş, M., 1984. Bağlama Elemanları Konstrüksiyon ve Hesap. Vol. 1, İTÜ Matbaas1, İstanbul.

14. Conrad Electronic International GmbH\&Co. KG, Aluminium Plate, https://www.conrad.de/ de/aluminium-platte-al-995-400-mm-200-mm2-mm-229825.html, [25/10/2016].

15. CG TEC GmbH, GFRP Epoxy Panel, http://www.carbonscout-shop.de/GFRPepoxypanel-350-X-150-x-2-mm.html, [25/10/2016].

16. Pfeiffer, P., Shakal, M., 1988. Effect of Bonded Metal Substrate Area and its Thickness on the strength and Durability of Adhesively Bonded Joints. Journal of Adhesion Science Technology. 12(3): 339-348. 